\section{The increased need for lifestyle interventions in dealing with non- communicable diseases in South Africa}

To the Editor: With over 54000 reported deaths associated with COVID-19 in South Africa (SA), the strong link between non-communicable diseases (NCDs) and bad outcomes is well established. ${ }^{[1]}$ NCDs are a pandemic in their own right. An inordinate amount of financial and human resources are being spent on this latter pandemic, yet in spite of advances in pharmaceuticals, technology and healthcare facilities, the incidence is rising unabated. ${ }^{[2]}$

One aspect that receives far too little attention is prevention dealing with the underlying causes. It is well recognised that NCDs are basically diseases of lifestyle behaviours. ${ }^{[3]}$ Trying to manage these diseases by medical management alone is a bit like the proverbial vigorous mopping of the floor of the flooding room without turning off the running tap.

To address this fundamental issue, the American College of Lifestyle Medicine was formed in 2004, and the American Board of Lifestyle Medicine started board examinations in 2017. The Lifestyle Medicine Global Alliance (established in 2015) oversaw the formation of numerous national entities such as the British Society of Lifestyle Medicine and the Australasian Society of Lifestyle Medicine. There are now some 20 national organisations around the world, the latest of these being the South African Lifestyle Medicine Association (SALMA). A number of well-recognised universities internationally are beginning to offer courses in lifestyle medicine (LM). ${ }^{[4-7]}$

LM is defined as the 'evidence-based practice of helping individuals and families adopt and sustain healthy behaviours that affect health and quality of life' (American College of Lifestyle Medicine). These interventions include a predominantly whole-food, plant-based diet, regular physical activity, adequate sleep, stress management, avoidance of risky substance use, and use of other nondrug modalities that promote health and prevent disease. LM can effectively prevent, treat or even reverse many chronic diseases such as hypertension, heart diseases, diabetes, obesity, depression/anxiety and musculoskeletal conditions.

LM is not complementary or alternative medicine - it is mainstream and evidence based..$^{[8]}$ Most national guidelines for chronic diseases acknowledge the foundational role of lifestyle interventions. ${ }^{[9]}$ But despite valid research findings supporting the benefits of LM, most healthcare providers remain unfamiliar with and/or sceptical about the usefulness of LM in the treatment and prevention of chronic diseases. Doctors and other health practitioners who utilise LM in their practice report benefits both for their patients and themselves. Additionally, studies have repeatedly confirmed that patient satisfaction with LM is very high. ${ }^{[10]}$

How do we at SALMA see our contribution to the field of medical practice in SA? Here are our objectives:

- Make LM training resources available for students in medicine and allied professions.

- Provide a forum for the sharing of experience and practical interventions in LM.

- Promote evidence-based LM as foundational to healthcare v. disease care, among both qualified practitioners and students.
- Advocate for the inclusion of LM in the medical curriculum in SA.

- Offer scientific support for consensus on specific lifestyle interventions in national guidelines in the management of chronic diseases.

Many doctors have become disillusioned with conventional 'disease care, which merely slows down or delays progression of chronic diseases. ${ }^{[11]} \mathrm{LM}$ offers the rewards of helping patients to achieve restoration of health and vitality in many if not most cases, through evidence-based principles. ${ }^{[12]}$ We invite correspondence and membership in this dynamic new field of medicine.

Author contributions. DG drafted the original letter, but all authors took part in editing and reviewing the manuscript.

\section{David Glass}

Specialist private practitioner, Port Shepstone, South Africa;

SALMA Board Chair

dglass@venturenet.co.za

Ernest John Muragijeyesu

Medical Officer, Ngwelezana Hospital, Empangeni, South Africa; SALMA Board Member

\section{Jennifer Bruentrup-Taylor}

Private Practitioner, East London, South Africa;

SALMA Board Member

\section{Sthokozile Myeni}

SALMA Board Member

\section{Lydia Altini}

SALMA Board Member

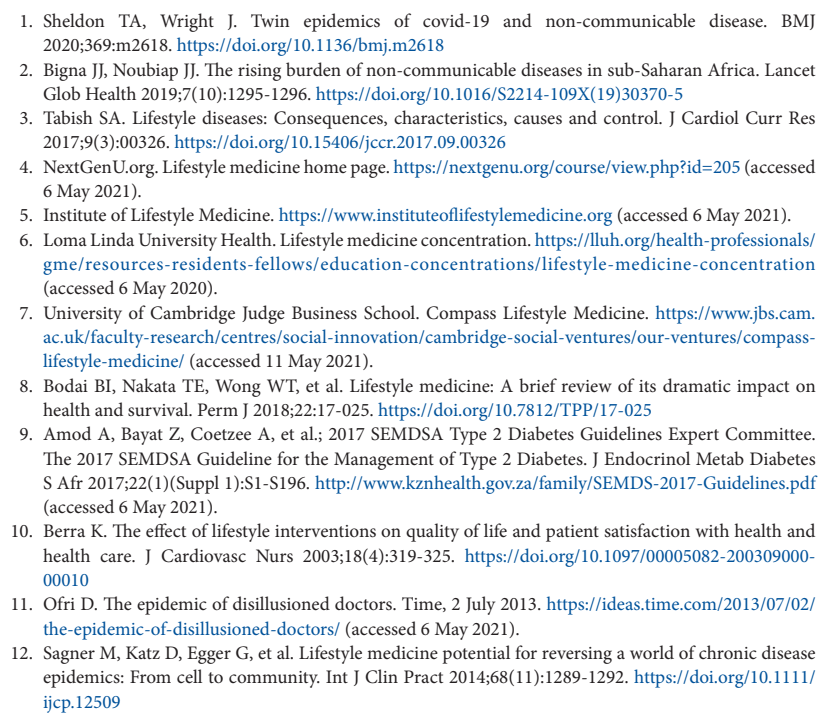
2020;369:m2618. https://doi.org/10.1136/bmj.m2618

2. Bigna JJ, Noubiap JJ. The rising burden of non-communicable diseases in sub-Saharan Africa. Lancet Glob Health 2019;7(10):1295-1296. https://doi.org/10.1016/S2214-109X(19)30370-5

3. Tabish SA. Lifestyle diseases: Consequences, characteristics, causes and control. J Cardiol Curr Res 2017;9(3):00326. https://doi.org/10.15406/jccr.2017.09.00326

4. NextGenU.org. Lifestyle medicine home page. https://nextgenu.org/course/view.php?id=205 (accessed 6 May 2021).

5. Institute of Lifestyle Medicine. https://www.instituteoflifestylemedicine.org (accessed 6 May 2021).

6. Loma Linda University Health. Lifestyle medicine concentration. https://lluh.org/health-professionals gme/resources-residents-fellows/education-concentrations/lifestyle-medicine-concentration (accessed 6 May 2020).

7. University of Cambridge Judge Business School. Compass Lifestyle Medicine. https://www.jbs.cam. ac.uk/faculty-research/centres/social-innovation/cambridge-social-ventures/our-ventures/compassac.uk/faculty-research/centres/social-innov
lifestyle-medicine/ (accessed 11 May 2021).

8. Bodai BI, Nakata TE, Wong WT, et al. Lifestyle medicine: A brief review of its dramatic impact on health and survival. Perm J 2018;22:17-025. https://doi.org/10.7812/TPP/17-025

9. Amod A, Bayat Z, Coetzee A, et al.; 2017 SEMDSA Type 2 Diabetes Guidelines Expert Committee. The 2017 SEMDSA Guideline for the Management of Type 2 Diabetes. J Endocrinol Metab Diabetes S Afr 2017;22(1)(Suppl 1):S1-S196. http://www.kznhealth.gov.za/family/SEMDS-2017-Guidelines.pd (accessed 6 May 2021).

10. Berra K. The effect of lifestyle interventions on quality of life and patient satisfaction with health and health care. J Cardiovasc Nurs 2003;18(4):319-325. https://doi.org/10.1097/00005082-20030900000010

1. Ofri D. The epidemic of disillusioned doctors. Time, 2 July 2013. https://ideas.time.com/2013/07/02/ the-epidemic-of-disillusioned-doctors/ (accessed 6 May 2021)

12. Sagner M, Katz D, Egger G, et al. Lifestyle medicine potential for reversing a world of chronic disease epidemics: From cell to community. Int J Clin Pract 2014;68(11):1289-1292. https://doi.org/10.1111/ ijcp. 12509

S Afr Med J 2021;111(6):517. https://doi.org/10.7196/SAMJ.2021.v111i6.15746 